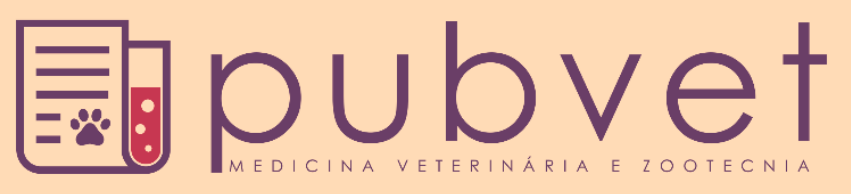

https://doi.org/10.31533/pubvet.v14n5a561.1-6

\title{
Leucemia linfoblástica aguda em felino: relato de caso
}

\author{
Iago Martins Oliveira ${ }^{1^{*}} \bullet$ D , Luísa Ferreira de Castro David Duarte ${ }^{2} \bullet$, Luís Eliam \\ Pereira $^{3}$, Adilson Donizeti Damasceno ${ }^{4}$ 政 \\ ${ }^{I}$ Médico Veterinário, Residente em Clínica e Cirurgia de Pequenos Animais, Universidade Federal de Goiás, Goiânia - Goiás, Brasil. \\ ${ }^{2}$ Discente em Medicina Veterinária, Universidade Federal de Goiás, Goiânia - Goiás, Brasil. \\ ${ }^{3}$ Médico Veterinário, Especializado em Clínica e Cirurgia de Felinos, Saúde Animal Clínica Veterinária, Goiânia - Goiás, Brasil. \\ ${ }^{4}$ Docente da Universidade Federal de Goiás, Departamento de Clínica e Cirurgia de Pequenos Animais, Goiânia - Goiás, Brasil. \\ *Autor para correspondência, E-mail: iago.vetufg@gmail.com
}

\begin{abstract}
Resumo. Dentre as formas clínicas de leucemia em pequenos animais, cita-se a leucemia linfocítica crônica e a leucemia linfoblástica aguda. A forma aguda é caracterizada por progressão rápida e responsividade baixa as modalidades terapêuticas. É mais relatada em felinos e os sinais clínicos são associados com os órgãos em que ocorre infiltração neoplásica, ou ainda alterações hematológicas. Os animais portadores de retroviroses são mais predispostos. $\mathrm{O}$ tratamento é baseado na utilização de fármacos quimioterápicos, antiinflamatórios esteroidais e tratamento suporte. Reforça-se a importância do diagnóstico precoce na sobrevida dos animais. Objetiva-se com o presente trabalho, descrever o caso clínico de um felino jovem com leucemia linfoblástica aguda, associada a infeção pelo vírus da leucemia felina. O diagnóstico final foi obtido após o óbito por meio do mielograma e, mesmo com tratamento suporte, os efeitos benéficos foram escassos e diante da condição clínica do paciente o tutor optou pela eutanásia.
\end{abstract}

Palavras chave: gato, mielograma, neoplasia, retrovirose

\section{Acute lymphoblastic leukemia in feline: case report}

\begin{abstract}
Among the clinical forms of leukemia in small animals, chronic lymphocytic leukemia and acute lymphoblastic leukemia are mentioned. The acute form is characterized by rapid progression and low responsiveness to therapeutic modalities. It is most commonly reported in felines and clinical signs are usually associated with organs in which neoplastic infiltration occurs or hematological changes occur. Viral carriers are more predisposed. Treatment is based on the use of chemotherapy drugs, steroid anti-inflammatory drugs and supportive therapy. The importance of early diagnosis is reinforced. The objective of this work is to describe a clinical case of a young feline with acute lymphoblastic leukemia associated with feline leukemia virus infection. The final diagnosis was obtained after death through the myelogram. Even with supportive treatment, the beneficial effects were scarce and in view of the patient's clinical condition the tutor opted for eutanásia.
\end{abstract}

Keywords: cat, myelogram, neoplasm, retrovirus

\section{Leucemia linfoblástica aguda en felino: reporte de caso}

Resumen. Entre las formas clínicas de leucemia en animales pequeños, se mencionan la leucemia linfocítica crónica y la leucemia linfoblástica aguda. La forma aguda se caracteriza por una rápida progresión y baja capacidad de respuesta a las modalidades terapéuticas. Es más frecuente en felinos y los signos clínicos suelen estar asociados con órganos en los que se produce una infiltración neoplásica o se producen cambios hematológicos. Los animales con retrovirus están más predispuestos. El tratamiento se basa 
en el uso de medicamentos de quimioterapia, medicamentos antiinflamatorios esteroides y terapia de apoyo. Se refuerza la importancia del diagnóstico precoz. El objetivo de este trabajo es describir un caso clínico de un felino joven con leucemia linfoblástica aguda asociada con la infección por el virus de la leucemia felina. El diagnóstico final se obtuvo después de la muerte a través del mielograma. Incluso con un tratamiento de apoyo, los efectos beneficiosos fueron escasos y se enfrentaron a la condición clínica del paciente que el tutor optó por la eutanasia.

Palabras clave: gato, mielograma, neoplasma, retrovirosis

\section{Introdução}

A leucemia é uma neoplasia maligna que tem origem em células precursoras hematopoiéticas. Os processos leucêmicos podem ser classificados com base na origem celular, sendo linfocíticas quando possuem origem linfoide ou mielocíticas quando a origem é mieloide. Nesse último caso, subclassificado em granulocítico, etritroide e megacariocítico (Greene et al., 1993; Nelson \& Couto, 2015). O nível de diferenciação também é considerado na caracterização. Contudo, está mais direcionado ao comportamento biológico da neoplasia (Zachary et al., 2012).

A leucemia linfoblástica aguda (LLA) apresenta evolução clínica rápida e os animais diagnosticados respondem de forma pouco efetiva ao tratamento. O diagnóstico pode ser estabelecido por meio da verificação de linfoblastos na circulação sanguínea e na medula óssea (Birchard \& Sherding, 2008). A sintomatologia clínica geralmente está associada aos órgãos em que há infiltração neoplásica e a redução de células hematopoiéticas (Thrall, 2015).

Em relação aos parâmetros hematimétricos, podem estar presentes anemia não regenerativa, neutropenia e trombocitopenia. Os gatos diagnosticados com essa doença geralmente são portadores do vírus da leucemia felina (FeLV), o que faz com que o prognóstico seja mais desfavorável (Birchard \& Sherding, 2008). Apesar da baixa resposta as opções terapêuticas, pode-se utilizar protocolos quimioterápicos, como por exemplo, ciclofosfamida, doxorrubicina, vincristina e prednisolona. Ademais, é recomendado tratamento suporte com analgésicos, imunoestimulantes, antibióticos e hemocomponentes, a depender da condição clínica do animal (Birchard \& Sherding, 2008).

O presente trabalho tem por objetivo relatar o caso de um felino doméstico com leucemia linfoblástica aguda associada à infecção pelo vírus da leucemia felina.

\section{Relato de caso}

Foi atendido em uma rotina hospitalar, um felino, macho, não castrado, sem raça definida (SRD), com três anos de idade, pesando 3,2 quilogramas e de pelagem branca. A tutora relatou durante a anamnese, que o animal foi resgatado quando filhote, era semi-domiciliado, estava prostrado há uma semana e apresentava emagrecimento progressivo. Também foram descritas alterações compatíveis com hipodipsia, inapetência e não havia informação sobre vacinação. Durante exame físico geral notou-se que o paciente estava apático, mucosa oral hipocorada, tempo de preenchimento capilar (TPC) de dois segundos, temperatura retal (TR) $37,8^{\circ} \mathrm{C}$, linfonodos normais à palpação, escore de condição corporal 2/5, frequência cardíaca (FC) 200 batimentos por minuto (bpm), pressão arterial sistólica (PAS) pelo método Doppler vascular $140 \mathrm{mmHg}$, frequência respiratória (FR) 46 movimentos por minuto (mpm), campos pulmonares limpos, turgor cutâneo aumentado, discreta distensão abdominal cranial e sem alterações na palpação da tireoide.

Com base no histórico clínico limitado, suspeitou-se de neoplasia abdominal, imunodeficiência viral felina (FIV) e FeLV. Foram realizados ensaio imunoadsorvente ligado a enzima (ELISA) rápido (Snap test combo $^{\circledR}$, Idexx, Cotia, SP, Brasil) para detecção de anticorpos da FIV e antígenos da FeLV, hemograma, perfil bioquímico com creatinina, ureia, alanina aminotransferase (ALT), fosfatase alcalina (FA) e bilirrubinas totais. Dentre os exames complementares solicitados, observou-se no perfil hematológico anemia macrocítica normocrômica com hematócrito $17 \%$ (valores de referência para espécie: 24 - 45\%), neutropenia, eosinopenia, acentuada leucocitose por linfocitose e presença de linfócitos atípicos (Figura 1). A amostra de sangue utilizada no teste ELISA foi reagente ao FeLV e as enzimas séricas solicitadas estavam dentro dos valores de referência para espécie. Diante do quadro de 
infecção por retrovírus, o paciente foi internado e realizou-se acesso venoso por meio da veia cefálica com auxílio de cateter vascular $\left(\mathrm{n}^{\circ} 22\right)$ para fluidoterapia de manutenção com solução de ringer com lactato, na taxa de infusão de $3 \mathrm{~mL} / \mathrm{kg} / \mathrm{h}$. Naquele momento foi mensurada a glicemia por intermédio de glicosímetro portátil (Accu-chek ${ }^{\circledR}$, Roche Diagnóstica Brasil Ltda, Jaguaré, SP, Brasil) que constatou $80 \mathrm{mg} / \mathrm{dL}$.

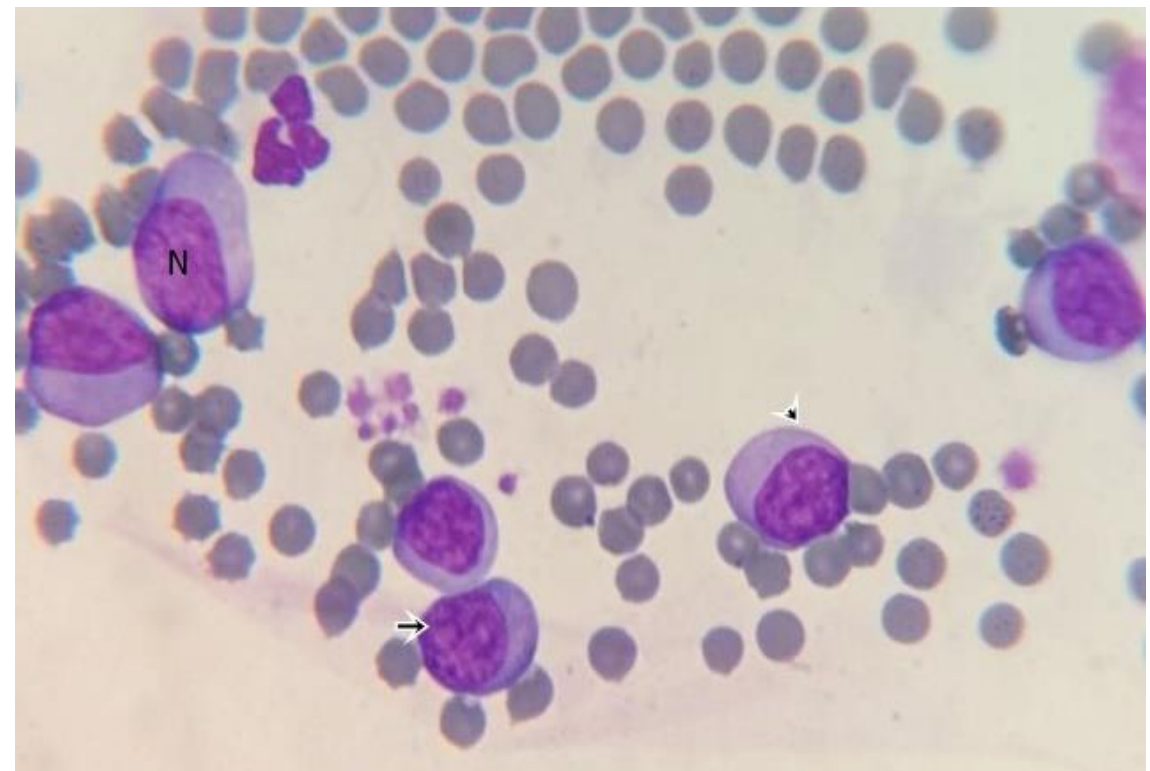

Figura 1. Esfregaço sanguíneo de felino jovem com leucemia linfoblástica aguda. Presença de células blásticas com morfologia linfoide (ponta da seta), macronucléolo evidente (seta maior) e núcleo celular exuberante em relação ao citoplasma (N). Panótico rápido, objetiva de 100x. Fonte: Laboratório de patologia clínica da Saúde Animal Clínica Veterinária.

No dia seguinte o paciente apresentava estado geral desfavorável. Realizou-se nova coleta de sangue para um segundo hemograma, que revelou persistência de anemia macrocítica normocrômica, leucocitose por linfocitose, monocitose e linfócitos atípicos. Foi solicitada ultrassonografia abdominal que evidenciou espessamento da parede gástrica e heterogeneidade esplênica com esplenomegalia. Diante da suspeita de distúrbio mieloproliferativo, foi realizada coleta de material para mielograma e no mesmo momento anestésico, realizou-se esofagostomia para implantação de sonda esofágica.

Após os procedimentos, o animal foi conduzido à internação com protocolo terapêutico de amoxicilina com clavulanato de potássio (Sandoz, Cambé, PR, Brasil, $250 \mathrm{mg} / 5 \mathrm{~mL}$ ) $20 \mathrm{mg} / \mathrm{kg}$ via oral, a cada 12 horas, cloridrato de tramadol (Teuto, Anápolis, GO, Brasil, $100 \mathrm{mg} / 2 \mathrm{~mL}$ ) $2 \mathrm{mg} / \mathrm{kg}$ via intramuscular, a cada 8 horas, dipirona (Teuto, Anápolis, GO, Brasil, $500 \mathrm{mg} / \mathrm{mL}$ ) $25 \mathrm{mg} / \mathrm{kg}$ via intravenosa, a cada 24 horas, meloxicam (Maxicam 0,2\% ${ }^{\circledR}$, Ourofino, Cravinhos, SP, Brasil) $0,1 \mathrm{mg} / \mathrm{kg}$ via intravenosa a cada 24 horas e alimentação pastosa 6 vezes ao dia feita pela sonda. O paciente permaneceu por três dias em acompanhamento sem mudança significativa dos parâmetros físicos e do estado geral. Realizou-se um último hemograma que revelou agravamento da anemia. Devido a situação clínica do paciente e o prognóstico desfavorável, os tutores optaram pela eutanásia. O exame necroscópico não foi autorizado.

O resultado do mielograma foi liberado dois dias após a eutanásia e revelou celularidade elevada, séries eritroide e mieloide em quantidade reduzida, porém com maturação completa. A relação mieloideeritroide (M:E) estava reduzida para espécie $(0,32$, valores de referência para espécie: $0,75-2,53)$. Verificou-se incontáveis células com morfologia linfocitária, grandes e com vários indícios de atipia, tais como macronucleólise, anisonucleólise, indentação nucleolar e nuclear, cromatina grosseira, leve aumento da relação núcleo:citoplasma, bem como intensa basofilia citoplasmática. Coexistia rica quantidade de corpúsculos linfoglandulares ao fundo laminar e não foram reconhecidos agentes etiológicos específicos associados (Figura 2). Face ao exposto, conclui-se quadro leucêmico agudo morfologicamente semelhante à LLA, associada à hipoplasia mieloide. 


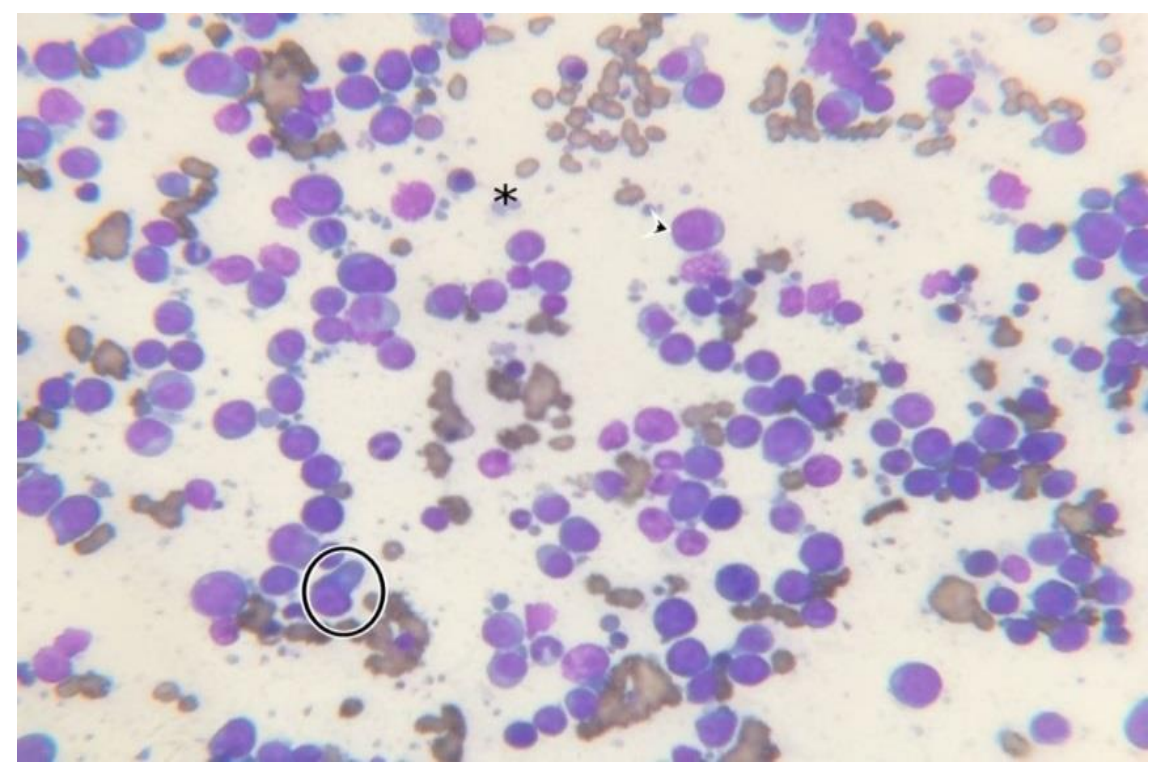

Figura 2. Aspirado de medula óssea de felino jovem com leucemia linfobástica aguda. Presença de macronucleose associada à sombra nucelar (cabeça da seta), corpos linfoglandulares (asterisco) e linfócito em espelho de mão (círculo preto). Panótico rápido, objetiva 40x. Fonte: Laboratório de patologia clínica da Saúde Animal Clínica Veterinária.

\section{Discussão}

Diante do quadro clínico-laboratorial apresentado, o diagnóstico foi de LLA. As leucemias são neoplasias hematopoiéticas e acometem as células linfoides, semelhante a descrição desse caso. Contudo, também podem acontecer em outros grupos celulares (Greene et al., 1993; Nelson \& Couto, 2015). Com base no que foi anteriormente exposto, o felino apresentava a forma aguda, portanto faz parte da classificação retratada por (Hnilica \& Patterson, 2011; Jain \& Jain, 1993) que sub-classifica baseado na maturidade das células envolvidas no processo.

Após a conduta clínica inicial, considerou-se o fato de ser um animal jovem, sem histórico de vacinação e com sinais inespecíficos. Posteriormente, foi solicitado teste ELISA que foi reagente ao FeLV, o que concorda com (Sparkes, 1997) sobre a utilidade clínica do teste rápido para triagem dos pacientes. A amostra biológica utilizada no ELISA foi o sangue total. Porém, recomenda-se soro ou plasma por considerar menor probabilidade de falsos positivos (Birchard \& Sherding, 2008). A abordagem foi conduzida com teste único e, desta maneira, não foi possível determinar se o paciente apresentava viremia primária, transitória ou persistente (Greene, 2006; Hartmann, 2012).

Este relato retratou informações a respeito de um animal da espécie felina, jovem, macho, não castrado, SRD e com acesso ao ambiente externo. Assim como é descrito por (Greene et al., 1993; Nelson \& Couto, 2015), gatos semi-domiciliados são mais diagnosticados com FeLV. Também está de acordo com a literatura (Gleich \& Hartmann, 2009), a alta prevalência da doença em gatos sem raça definida e com contactantes. Clinicamente, o paciente apresentou alteração de consciência e no estado de hidratação. Apesar dos parâmetros vitais regulares, observou-se hiporexia e emaciação progressiva, ratificando a inespecificidade dos sinais clínicos de um gato FeLV positivo (Lutz, 1990; Sparkes, 1997). Ao exame físico observou-se discreta distensão abdominal, palidez de mucosas e desidratação. Neste caso, somente o aumento de volume do abdome reforça a citação de (Norsworthy et al., 2004) que descreveram que essa alteração está relacionada ao desenvolvimento de neoformações ou organomegalia. A inclusão de evidências compatíveis com efusão pleural, anormalidades intraoculares e dermatopatias não foram verificadas ao exame físico.

As alterações hematológicas observadas na descrição desse caso foram anemia, neutropenia, eosinopenia, leucocitose por linfocitose, monocitose e presença de linfócitos atípicos, tal como observado em distúrbios hematopoiéticos neoplásicos e não neoplásicos associados às retroviroses felinas (Greene, 2006; Hartmann, 2012). Todavia, antagonicamente ao que também consta nos estudos supracitados (Greene, 2006; Hartmann, 2012), o paciente relatado não apresentou anormalidades plaquetárias. 
A anemia verificada foi macrocítica normocrômica, o que foi considerado uma consequência comum da infecção por FeLV e, por isso, essa virose é uma das causas mais importantes de quadros anêmicos em gatos (Lutz, 1990; Sparkes, 1997). Com base na resposta eritropoiética evidente no sangue periférico, não havia indícios de resposta regenerativa, tais como, policromasia, anisocitose, metarrubrícitos e corpúsculos de Howell-Jolly (Lutz, 1990; Sparkes, 1997). A leucocitose por linfocitose foi observada em todos os exames solicitados. Entretanto, linfopenia por efeito citopático viral já foi descrita em $70 \%$ de felinos com FeLV (Gleich \& Hartmann, 2009). A neutropenia persistente é comum em casos de FeLV (Lutz, 1990; Sparkes, 1997), foi observada neste caso e pode representar causa do desenvolvimento de doenças oportunistas, porém não foram observadas evidências clínico-laboratoriais dessas doenças no animal do caso aqui descrito. Além da ausência de infecções concomitantes, diferentemente ao observado na literatura (Birchard \& Sherding, 2008; Hartmann, 2012) também não foram verificados indícios de distúrbios imunomediados, linfadenopatias, desordens reprodutivas e neuropatias. Os linfonodos estavam normais à palpação e não houve evidência de linfadenomagalia (Birchard \& Sherding, 2008) de linfonodos abdominais ao exame ultrassonográfico. Também não foram identificados sinais neurológicos descritos em gatos com FeLV (Hartmann, 2012) como síndrome de Hörner, amaurose e anisocoria.

Em todos hemogramas solicitados foram constatados linfócitos atípicos, o que contribuiu para a suspeita de distúrbio mieloproliferativo. De acordo com (Avery \& Avery, 2007), gatos com número exacerbado de linfoblastos circulantes podem ser diagnosticados com leucemia aguda por meio do hemograma, mas nesse caso optou-se por uma melhor classificação com a solicitação da análise da medula óssea. No mielograma, a relação M:E estava reduzida conforme descrito para animais com hipoplasia mielóide em casos de doenças mieloproliferativas (Thrall, 2015). Também foram vistos linfoblastos grandes, com cromatina grosseira, alteração na relação núcleo:citoplasma, macronucleólise, anisonucleólise e intensa basofilia citoplasmática. Esses achados se assemelham parcialmente com o descrito por (Thrall, 2015), que caracterizou essas células como pequenas ou grandes, com núcleo arredondado ou oval, cromatina pontilhada, presença de um ou mais nucléolos, citoplasma azul claro que podem ter grânulos azurofílicos finos ou grosseiros.

De acordo com todos esses achados, o diagnóstico baseou-se na morfologia celular e concluiu-se se tratar de um quadro leucêmico de LLA. Contudo, para uma diferenciação mais detalhada faz-se necessário exames de imunofenotipagem ou citoquímicos (Thrall, 2015), que não foram realizados. A situação desfavorável do paciente fez com que somente o tratamento suporte fosse realizado e devido à gravidade do caso, os tutores optaram pela eutanásia. Entretanto, sabe-se que existe a opção de utilizar terapia antiviral, imunomoduladora e antineoplásica, como por exemplo, interferons, associação de vincristina, prednisolona, L-asparaginase, eritropoietina e terapia suporte com antibióticos, analgésicos e transfusão sanguínea.

\section{Conclusão}

As desordens mieloproliferativas em gatos são frequentemente associadas às retroviroses, o que confere piora no quadro clínico. Ressalta-se a importância da avaliação do mielograma para o diagnóstico dos processos leucêmicos em pequenos animais. A LLA é uma doença de curso clínico rápido e, mesmo com diagnóstico precoce, o prognóstico do caso relato foi desfavorável.

\section{Referências bibliográficas}

Avery, A. C., \& Avery, P. R. (2007). Determining the significance of persistent lymphocytosis. Veterinary Clinics of North America: Small Animal Practice, 37(2), 267-282.

Birchard, S. J., \& Sherding, R. G. (2008). Manual Saunders: clínica de pequenos animais. In Ed. Roca (Vol. 3).

Gleich, S., \& Hartmann, K. (2009). Hematology and serum biochemistry of feline immunodeficiency virus-infected and feline leukemia virus-infected cats. Journal of Veterinary Internal Medicine, 23(3), 552-558.

Greene, C. E. (2006). Fatores ambientais de doeçnas infecciosas. In E. D. Ibid (Ed.), Doenças infecciosas em cães e gatos. Elsivier. 
Greene, C. E., Samperio, J. O., \& Gómez, J. P. (1993). Enfermedades infecciosas: Perros y gatos. Editora Interamericana.

Hartmann, K. (2012). Clinical aspects of feline retroviruses: a review. Viruses, 4(11), 2684-2710.

Hnilica, K. A., \& Patterson, A. P. (2011). Small animal dermatology: a color atlas and therapeutic guide. Elsevier Health Sciences.

Jain, N. C., \& Jain, A. H. (1993). Essentials of Veterinary Hematology (1st ed.). Wiley-Blackwell.

Lutz, H. (1990). Feline retroviruses: a brief review. Veterinary Microbiology, 23(1-4), 131-146.

Nelson, R. W., \& Couto, C. G. (2015). Medicina interna de pequenos animais (Issue 1). Elsevier Editora.

Norsworthy, G. D., Crystal, M. A., Grace, S. F., \& Tilley, L. P. (2004). O paciente felino. São Paulo: Roca, 3, 300.

Sparkes, A. H. (1997). Feline leukaemia virus: a review of immunity and vaccination. Journal of Small Animal Practice, 38(5), 187-194.

Thrall, M. A. (2015). Hematologia e Bioquímica Clínica Veterinária. In 2. ed. Editora Roca.

Zachary, J. F., McGavin, D., \& McGavin, M. D. (2012). Bases da patologia em veterinária. Elsevier Brasil.

Recebido: 26 de outubro, 2019.

Aprovado: 27 de novembro, 2019.

Disponível online: 4 de maio, 2020.

Licenciamento: Este artigo é publicado na modalidade Acesso Aberto sob a licença Creative Commons Atribuição 4.0 (CC-BY 4.0), a qual permite uso irrestrito, distribuição, reprodução em qualquer meio, desde que o autor e a fonte sejam devidamente creditados. 